\title{
Sustainable Development and Future Mining Engineers' Competitiveness: Axiological and Personality Aspects
}

\author{
Dina Shalimova ${ }^{1, *}$ \\ ${ }^{1}$ Kemerovo State University, 650000, 6 Krasnaya St., Kemerovo, Russia
}

\begin{abstract}
In line with the person-centered approach, the article deals with the 'competitive ability' of the future mining engineer from psychological and pedagogical points of view. The axiological and personal agency criteria of competitiveness are accentuated. The role of self-esteem in the system of value-oriented and motivational parameters of the competitive graduate is identified. Methods of research are: polling, diagnostic testing. The research exposed self-acceptance of competitive qualities as one of the factors of the graduate's competitive ability development. The exposed factor can be used for further elaboration of potential competitiveness criteria and considered when creating the corresponding pedagogical environment in the "Mining engineering" training program.
\end{abstract}

\section{Introduction}

Improving the competitiveness and training of engineers for the mining industry concerns both vocational and psychological lines of growth for future experts. The notion of professional competencies is often denoted by the expression 'hard skills' in some modern literature, and, accordingly, the term 'soft skills' is sometimes used to mean abilities for critical thinking, communication, collaboration, creativity, adaptability, etc. [1]. In our opinion, soft skills, as they are, in detachment from a definite profession and from the system of values and value-based orientations of the graduate, does not have enough predictive significance. When we speak of the 'competitive ability' of a specialist possessing a competence, the expression (soft skills) suggests itself more as a metaphor than a scientific term, because competence is a wider notion including both skills and personal qualities. We also share the idea that the quality of specific work done and the psychological constituent are interrelated things [2-3]. That is the reason why we resort to the term 'personality qualities' while describing everything above the mining engineer's expertise.

During the university's studies the systematization and building up of the graduates' own scale of values takes place. They become more confident and able to realize their initiatives - a qualitative change that J. Raven called self-initiated competences [4]. Deepening of the value attitude to the reality, having a better grasp of the real world and future profession - all that leads to adequate self-awareness and clear life perspective. It is the period when reasonable self-esteem is formed which will allow the future mining engineer to apply for

* Corresponding author: kemsu@,kemsu.ru 
prospective employment within the industry, or will force to re-make the choice of the life path.

Putting the question of how the values of future professionals and their competitiveness are correlated, we rely on the idea of G. Allport about the unity of values and personal qualities inherent in a socially mature person who maintains good social awareness [5]. According to G. Allport, mature persons do things in keeping with what they really are. This is called propriate functioning. (Propriate comes from the word proprium, which is a selfconcept). Viewing G. Allport's characteristics of maturity in the context of competitiveness, we consider the most relevant features to be:

- Involvement (as extensions of Self)

- Problem-centeredness and development of problem-solving skills

- Self-insight (the image of own abilities, status, behavior)

- Acceptance of oneself (emotional security and propriety)

- Motivation (personality orientation).

- A unifying philosophy of life and a personalized conscience

The last feature (function) predominates and fosters the others. Due to the personalized conscience a young man / woman becomes the subject of cognitive ability, learning to apprehend the laws of social and individual development, the subject of activity changing the outer world. In other words, he / she acquires personal agency.

Based on G. Allport's views, modern psychologists highlight various signs of personal agency: initiative, self-reliance, awareness, purposefulness, responsibility, individuality, creativity, success, constructiveness, ability and willingness to cooperate, etc. Being in the university educational environment, future mining specialists are included in the specific system of relationships, interests, values and undergo the intensive process of the personalitycentered unfolding. Thus, creating the conditions for the formation of the graduates' personality qualities, we have identified the following criteria: personal agency criterion and axiological (values-based) criterion of competitiveness of future mining engineers.

\section{Materials and methods}

Learning the mining profession and acquiring the necessary competencies is dependent on the development of the graduate's personal agency. The most indicative features to characterize this criterion, in our opinion, are the following: self-reliance, initiativity, responsibility, determination (commitment). To establish the levels of personal agency we created a questionnaire-like scheme on which the students were estimated by a group of experts (tutors) according to the respondents' participation in the educational process.

Students, who independently solved their educational and organizational problems, received the maximum score according to the indicator of "self-reliance" because their desire for "adulthood", lack of guardianship, active manifestation of themselves in society was important. They independently chose the enterprise for vocational practice, classes from a wide range of extra-curriculum activities (student construction brigades, sport, patronage work, scientific and socially significant projects, etc.).

Future specialists, who received the maximum score in terms of initiativity were the organizers of creative teams, clubs for interests, developers and independent implementors of socially significant projects, putting forward their own proposals to improve the university environment. Respondents who put forward but did not implement public initiatives received a lower score, and the absence of any initiatives was assessed minimally.

The attitude of future professionals to work in student associations, organizations, action groups, etc. was considered a sign showing the level of responsibility. The formation of responsibility as an integrative quality of personality extends to the social interactions of future professionals - hence it improves their competitiveness. Therefore, the maximum 
ratings on the indicator of responsibility were received by the leaders of student organizations or those tending to the leading position (commanders, commissioners, heads of sectors of student units, initiative groups). Close to the maximum assessments were received by members of initiative groups, student units - that is, people carrying collective responsibility for the affairs of a unit or a group.

The indicator of determination (commitment), characterized students depending on how they feel about their goals: (a) "always achieve the goal"; b) "making efforts to achieve the goal, respecting motivated people"; (c) "not always achieve the goal"; d) don't think about goals."

Within the axiological criterion of mining engineers' competitiveness, we assessed the maturity of their world outlook, attaching a special importance towards such values as the realization of abilities for the benefit of society, personal success in the profession; respect of friends, improvement of ecological_knowledge. Differences in the complex and nature of the values developed by the future mining engineers were revealed in the priorities demonstrated by them. To determine the levels of competitiveness on this criterion, we developed a questionnaire, through which the respondents indicated those of the proposed values, which are the most meaningful for them. In this way, the indicators showed allowed us to identify groups of high, medium and low levels of competitiveness on this criterion.

The high level of the axiological criterion was characterized by a broad representation of social values in the structure of values. Future specialists demonstrated the following range of social values: "realization of abilities for the benefit of society," "personal success in the profession," "respect of friends," "improving ecological knowledge," "material wealth as a means of personal improvement, personal autonomy, help to loved ones." The middle level of the axiological criterion was characterized by partial representation of social values in the structure of students' values: among the significant values the respondents noted "respect of friends", "material wealth", but did not note the values of "realization of abilities for the benefit of society", "personal success in the profession," "improvement of environmental knowledge." The low level of the criterion was characterized by the lack of social values of self-realization among the future professionals and the presence of the value of "material wealth" and "vital" values. That may be a warning sign of possible underdevelopment of personality [6-7].

Personal values are classified by modern psychologists depending on the motivational types of individuals [8]. To couple value-based orientations with the motivation of the respondent students we studied the individuals' motivation. It has been known since 1960s, that the majority of human motives are classified as the needs for achievement, affiliation, and power, and a person's effectiveness in certain jobs is influenced by these three needs [910]. In our mind, this theory is directly applicable to the training of mining engineers, taking into account that their future job is highly demanding, especially for solving urgent problems while directing incident response activities.

The need for achievement is the extent to which the specialist desires to perform difficult and challenging tasks successfully. A high need for achievement means strive for positive feedback related to the performance on the tasks. The need for affiliation is the desire for harmonious relationships with the people of the group [9]. Engineers with high need for affiliation prefer to feel accepted by their subordinates. It would make the communication easier when a mining engineer has to function, for example, as the incident commander. The need for power is a desire for authority, being in charge. The manifestation of each of the three motivators of student activity was calculated by us as the sum of points determined from the evaluation of five diagnostic test approvals on a 5-point scale. 


\section{Results and Discussion}

Based on the questionnaires received for each student, the number of points was calculated, allowing to group the respondents as having maximum, average and low competitive performance rates by the two main criteria. The survey was conducted at the initial stage and middle stages of training. At the end of the study, there was a significant increase in the number of future high-level professionals on the personal agency criterion of competitiveness. The group of middle-level students increased slightly, and the number of students whose competitiveness was classified as low by that criterion more than halved. (see Tab. 1).

Most future specialists noted the emergence and development of sociability, ability to express themselves, self-presentation. Interviews with future engineers showed that they began to analyze different situations more often in terms of morality, tolerance of their behavior. Participants in extra-curriculum socially significant activities felt that they had become more self-reliant and independent in decision-making, more erudite, and gained organizational skills.

In order to form a value-based attitude of students to the world around them, to form beliefs, according to which socially significant actions are consciously committed, future specialists were involved in the educational process of the university through mentoring, leadership, and organization of socially significant activities. They were the initiators and participants in programs aimed at deepening moral and ethical, ecological, humanitarian, civil, legal, psychological and educational knowledge [11-12]. As a result, students developed a strong interest in social problems, increased the desire for self-fulfillment as the most important value. So, at the final stage of the research, "realization of abilities for the benefit of society" was a typical choice for students of a high-level group of competitiveness which amounted to $83 \%$. At the initial stage of education, only $44 \%$ of respondents had a predominance of social values.

The number of mid-level respondents decreased by more than 3 times compared to the beginning of the study and amounted to $11 \%$. The number of future specialists of low level of competitiveness on this criterion (for whom the main value was material wealth for meeting "vital" needs, and the values of self-fulfillment, personal success in the profession, respect of friends were absent) decreased to $6 \%$, that is, three times compared to the beginning of the research. By the end of the study, fewer future professionals had noted the presence of the so-called value-tools: "Getting education to make money, no matter what area of activity." More students noted that they had socially significant goals; the number of future specialists taking part in the design of extra-curriculum activities has increased.

Table 1. Changes in the future mining engineers' competitiveness during the study periods, $\%$ $(\mathrm{n}=150)$.

\begin{tabular}{|c|c|c|c|c|}
\hline \multirow{2}{*}{$\begin{array}{c}\text { Competitiveness } \\
\text { level / Criteria }\end{array}$} & \multicolumn{2}{|c|}{ Axiological } & \multicolumn{2}{c|}{ Personal agency } \\
\cline { 2 - 5 } & $\begin{array}{c}\text { Start of } \\
\text { research }\end{array}$ & $\begin{array}{c}\text { End of } \\
\text { research }\end{array}$ & $\begin{array}{c}\text { Start of } \\
\text { research }\end{array}$ & $\begin{array}{c}\text { End of } \\
\text { research }\end{array}$ \\
\hline High & 44 & 83 & 17 & 45 \\
\hline Middle & 38 & 11 & 27 & 28 \\
\hline Low & 18 & 6 & 56 & 27 \\
\hline
\end{tabular}


Exploring the competitiveness of the university graduates, we assume that the persons' self-development is stimulated by their self-esteem which is at the same time one of the most important personal criteria. We studied students' self-assessment of their competitive qualities using questionnaires. A list of the main qualities potentially characterizing a competitive personality was offered to students in the form of a questionnaire with the instruction: "Note the qualities that you think are distinctive of you." The results of the survey showed that the first place was taken by the quality of "sociability" $(80 \%)$, the second - by responsibility $(65 \%)$, the third - by self-confidence $(58 \%)$. Leadership qualities and practicality were characteristic of $30 \%$ of respondents.

We compared these data with the results of diagnostic testing of the motivators governing the subject's socio-psychological activity: the desire for success / achievement; the desire for power; trend towards affiliation (see tab. 2). The respondents' positions were grouped on these three types of activity trends. For example, the statement "I like to work in a group more than alone" characterized the desire for group recognition and respect; the statement "I like to set real goals and accomplish them" characterized the desire for success.

Table 2. Trends in socio-psychological activity of future engineers $(n=150)$.

\begin{tabular}{|c|c|c|}
\hline $\mathbf{N N}$ & $\begin{array}{c}\text { Motivators } \\
\text { regulating activity }\end{array}$ & $\begin{array}{c}\text { Assessment of the need } \\
\text { on average (in points) }\end{array}$ \\
\hline 1 & Need for affiliation & 22 \\
\hline 2 & Need for achievement & 19 \\
\hline 3 & Need for power & 7 \\
\hline
\end{tabular}

The data in Table 2 show that the dominating trend in the implementation of graduates' activity is their desire for group recognition and respect, and the least important for them is the desire for power. The diagnostic testing results are consistent with the students' survey of self-assessment of significant personality traits. In the students surveyed, the average assessment of the tendency to strive for group recognition and respect (affiliation) was prevailing, which finds its external manifestation in the high importance of the quality of "sociability". The tendency to achieve success, characteristic of responsible and confident students, took the second position. The "need for power" received a minimum number of points, showing itself in the assessment of leadership qualities only 30 percent of respondents.

The results obtained are comparable with A.V. Koteneva and P.V. Chelyshev's view that students, active and initiative in communication, showing interest in the social environment, are able to maintain their self-esteem. It has been experimentally establised that they can keep the balance in conditions of uncertainty, and constant stress factors, better cope with isolation and withstand long and repeated stressors [13]. The authors' psychological observation also reveals the fact that "the most difficult thing is to show resistance to factors that represent a threat to a positive image of «Self»" [13]. The above comparison allows us to consider the self-assessment of the competitive qualities as one of the parameters of the value-motivational system of the mining engineer' personality. The constituent parts of competitiveness, including self-assessment, are presented in Figure 1 as elements of a general circuit scheme. 


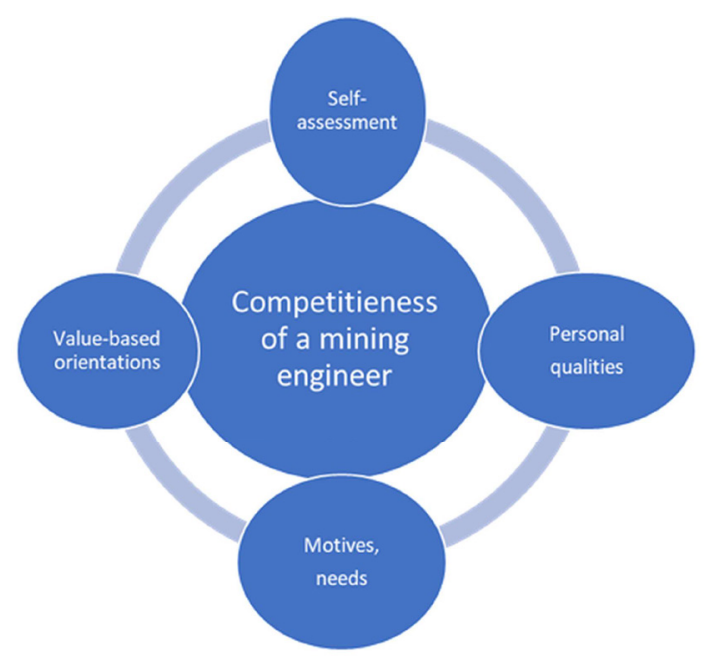

Fig. 1. Constituent parts of the of a mining engineer's competitiveness from the pedagogical and psychological points of view.

It is the system of emotional-evaluation relationships that sets the hierarchical structure of the dominant motives, which encourages the person to assert in the activity and manifest the best professional qualities.

\section{Conclusion}

The mining engineers' job requires a willingness to experience a great tension of spiritual and physical forces. They must be prepared to be responsible not only for themselves, but also for other people in the team, particularly in stressful situations of uncertainty and emergency. So, for sustainable development of the mining industry dependable, effective, resourceful specialists are needed. But these qualities should not be analyzed in isolated way, apart from the values-based orientations of the graduate, including realization of individual potential for the benefit of society, the industry and the person him / herself. In the university educational environment future mining engineers should develop self-confidence, criticalness of the mind, a caring attitude to the environment - the qualities opposite of inertia, indifference. Based on the above and the positive correlation between self-esteem and future aspirations, noted by the researchers [14], we conclude that the graduate's self-acceptance of the qualities mentioned and positive image of «Self» are proven to be a factor of improving future mining engineers' competitiveness. This should be taken into consideration when creating the corresponding pedagogical environment in the mining engineering educational system.

\section{References}

1. M. Wats, R.K. Wats, International Journal of Learning, 15, 12 (2009)

2. M. Cubel, A. Nuevo-Chiquero, S. Sanchez-Pages, M. Vidal-Fernandez, The Economic Journal, 126(592), 654-681 (2016)

3. E.C. Short, Competence: Inquiries into its Meaning and Acquisition in Education Settings (University Press of America, Lanham, 1984) 
4. J. Raven, Managing Education for Effective Schooling: The Most Important Problem Is to Come to Terms with Values (Unionville, New York, 1994)

5. G.W. Allport, Pattern and growth in personality (Rinehart and Winston, Holt, 1961)

6. E.S. Ellis, L.A. Worthington, Reseach Synthesis on Effective Teaching Principles and the Design of Quality Tools for Educators (University of Oregon, 1994)

7. P.V. Chelyshev, European Journal of Natural History, 1, 18-20 (2015)

8. S.H. Schwartz, Values and behavior: Taking a cross-cultural perspective (Springer, New York, 2017)

9. D.C. McClelland, The Achieving Society (Van Nostrand, Princeton, 1961)

10. H. Heckhausen, Motivation und Handeln. Lehrbuch der Motivationspsychologie (Springer, Berlin, 1985)

11. L.V. Almyashova, D.V. Shalimova, European Applied Sciences, 1, 108-110 (2012)

12. D.V. Shalimova, G.A. Zhdanova, Modern scientific research and their practical application, J, 21315 (2015)

13. A.V. Koteneva, P.V. Eurasian mining, 1, 84-88 (2020)

14. M.W. Baldwin, L. Sinclair, Journal of Personality and Social Psychology, 71(6), 11301141 (1996) 